\title{
Cirrus Clouds and Their Response to Anthropogenic Activities
}

\author{
Bernd Kärcher ${ }^{1}$ (D) \\ Published online: 1 February 2017 \\ (C) The Author(s) 2017. This article is published with open access at Springerlink.com
}

\begin{abstract}
Cirrus clouds are ubiquitous, long-lived, highlevel ice clouds that exert a considerable global radiative effect on the climate system. This review assesses recent observational and modeling evidence of how anthropogenic activities might affect cirrus. Changes in physical properties and chemical composition of liquid aerosol particles will unlikely affect cirrus significantly, but anthropogenic influences may occur through changes in heterogeneous ice nuclei. Two main uncertain factors contribute to the current inability to constrain background cirrus formation: small-scale variability in dynamical forcings that drive ice nucleation parameterizations and the ability of airborne particles to act as efficient heterogeneous ice nuclei. These uncertainties keep us from drawing robust conclusions about anthropogenic influences on cirrus. Microphysical and macrophysical representation of cirrus in global models must first be advanced before we can predict changes in climate with fewer uncertainties. Some climate intervention studies suggest a potential cooling effect of deliberately perturbed cirrus, but at the risk of modifying precipitation inadvertently.
\end{abstract}

Keywords Climate change $\cdot$ Cirrus clouds $\cdot$ Anthropogenic impacts $\cdot$ Ice formation $\cdot$ Climate models $\cdot$ Predictions

This article is part of the Topical Collection on Aerosols and Climate

Bernd Kärcher

bernd.kaercher@dlr.de

1 Deutsches Zentrum für Luft- und Raumfahrt (DLR), Institut für Physik der Atmosphäre (IPA), Oberpfaffenhofen, Germany

\section{Introduction}

Cirrus are high-altitude $(>8 \mathrm{~km})$ ice clouds lacking a liquid cloud water phase. Ice crystals in cirrus are detrained from convective (anvil cirrus) or frontal cloud outflow or they form at low temperatures $(<230 \mathrm{~K})$ in situ in the upper troposphere and tropopause region not directly associated with convection. Aircraft-produced contrail cirrus - the only man-made type of clouds-comprise line-shaped contrails and irregularly shaped cirrus clouds evolving from them. Glaciated liquidphase clouds in the mid- and lower troposphere are not classified as cirrus. This distinction is meaningful owing to the widespread global occurrence [1] and unique role of high ice clouds in radiative-convective feedbacks [2]. The morphologies of various cirrus cloud types and the high degree of variability in their physical properties are largely imparted by the meteorological environment in which they form. Most cirrus are vertically thin, often separated from lowlevel clouds and develop in thermodynamically stable environments. Moreover, cirrus tend to be long-lived, cover large areas, and exert a considerable global radiative forcing of climate [3]. Factors controlling cirrus include small- and largescale atmospheric dynamics, ice-nucleating properties of natural and anthropogenic aerosol particles and, in the case of optically thicker cirrus, interactions with radiation.

Cirrus clouds modify the planetary radiation budget, influence hydrological and climate sensitivities, and affect surface climate. Cirrus absorb upwelling terrestrial radiation very effectively and can be strong reflectors of incident solar radiation. Most types of cirrus are optically thin at solar wavelengths and induce an average net warming resulting from a slight imbalance between shortwave and longwave forcings. The climate sensitivity predicted by general circulation models (GCMs) is sensitive to uncertainties in the microphysical representation of cirrus [4]. High clouds contribute about $1 / 3$ to the total cloud 
feedback estimated from GCMs [5]. Changes in the amount of the highest, thus coldest and optically thinnest, cirrus have a large effect on outgoing longwave radiation (OLR) and help sustain the Hadley circulation by enhancing subsidence over dry regions at low latitudes. Many tropical cirrus can be traced to deep convection [6]. How high cloudiness responds to global warming may depend on the clustering of precipitating tropical clouds [7]. Stratiform anvil cirrus originating from mesoscale convective systems are optically thick at least in the initial stages of their life cycle and exert a substantial influence on the tropical circulation via cloud-radiation-convection-precipitation feedbacks. While trapping of longwave radiation heats the tropical upper troposphere and stabilizes convectively perturbed regions, cloud top longwave cooling destabilizes those regions. Constituting the last dehydration step in tropospheric air entering the stratosphere, optically very thin (subvisible) cirrus in the tropical tropopause layer (TTL, 13-19 km) above the level of mean deep convective outflow affect water vapor concentrations [8]. TTL cirrus are considered to be an important component in determining how changes in the moisture content of the stratosphere impact decadal climate predictions [9].

A first step towards quantifying anthropogenic influences on cirrus is to help formulate important questions addressing the current understanding of cirrus and parameterization issues associated with them. At this stage, I regard this as important as to find scientifically sound answers. After discussing major cirruscontrolling factors and various pathways of how cirrus might be affected by anthropogenic activities inferred from recent observational and modeling studies, I illustrate some of the pending scientific challenges regarding the representation of cirrus in models. The future outlook section suggests possible ways forward.

\section{Dynamical and Microphysical Controls of Cirrus}

Cirrus cloud formation is initiated by dynamical forcing acting across a wide range of scales generating conditions conducive to ice crystal formation. Ice supersaturation relevant to cirrus development is set by synoptic meteorology. Synoptic cold pools define the confines of cirrus cloud existence, as demonstrated by the similarity between large-scale patterns of cirrus occurrence and ice supersaturation and its variability $[10,11]$. Micro-scale conditions of moisture and temperature govern ice crystal formation. Small-scale vertical air motion variability is key in determining pristine ice crystal number concentrations. It needs to be considered in cirrus ice formation alongside aerosol effects in efforts to ascribe cause to changes in cirrus cloud properties $[12,13]$. The prevalence of mesoscale vertical wind fluctuations in the upper troposphere and lower stratosphere has been confirmed time and again by a number of observational techniques including aircraft and cloud radar [14], super-pressure balloons [15], and wind profiler [16]. Variability in vertical air velocities causes a major portion of ice crystal number variability in a global model [17]. In nature, much of this variability is brought about by internal gravity waves, the effects of which are readily apparent in many radiosonde soundings. Breaking gravity waves are potent sources of small-scale turbulent mixing potentially affecting ice nucleation. Wave-turbulence interactions in sheared flows are difficult to study in observations and to simulate in numerical models.

Particles are required to mediate the formation of ice crystals in cirrus. Ice nucleation refers to the first appearance of a stable ice phase. Airborne particles comprise supercooled aqueous aerosol and cloud water droplets that may freeze homogeneously and a special subset of solid particles (ice nuclei, IN) that nucleate ice crystals heterogeneously. While the background upper tropospheric aerosol is relatively well characterized, information on physical properties of cloud droplets in cold cloud outflow regions is sparse. Fewer than 1 in 1000 of ambient particles acts as IN and not all of them form ice efficiently. In conditions of weak dynamical forcing, efficient IN exert an influence on cold cloud formation that is disproportionate to their low abundance. Inferring nucleation mechanisms from atmospheric measurements is challenging and the experimental characterization of ice crystal precursor particles at cirrus levels is an active area of research [18]. Lack of knowledge of IN abundance and their propensity to form ice together with the poor representation of atmospheric IN distributions in global models weakens efforts to reduce the strong sensitivity of climate projections to assumptions regarding cloud ice nucleation [19].

Anthropogenic activities influence cirrus cloud properties and occurrence, hence their role in a perturbed climate, via dynamical and microphysical pathways. Cirrus clouds will be altered by changes in the characteristics of small- and large-scale dynamical forcing, changes in abundance and properties of ice-active aerosols, and changes in other clouds (Table 1). Those changes are in various ways tied to anthropogenic activities. Ice clouds are not well represented in GCMs and show disparate responses in climate change experiments [20]. This makes it difficult to assess with confidence how cirrus properties and atmospheric effects are influenced by anthropogenic activities or how they will change in the future. Upper tropospheric ice clouds should receive high priority in efforts to improve cloud schemes of GCMs due to their possible effects on convective mesoscale organization, hence, climatic and hydrological sensitivities [21].

\section{Detecting and Quantifying Cirrus Changes}

Besides active and passive remote sensing, experimental techniques used to study cirrus clouds include in situ measurements of the physical properties of ice crystals using particle probes 
Table 1 Anthropogenic factors causing cirrus cloud changes and the likelihood and scale of their impact. The potential of those factors to change natural cirrus in the future is also included

Anthropogenic impacts on cirrus clouds

\begin{tabular}{|c|c|c|c|c|}
\hline Cirrus-controlling factor & $\begin{array}{l}\text { Assumed future } \\
\text { changes }\end{array}$ & Natural cirrus changes & $\begin{array}{l}\text { Likelihood of } \\
\text { impact }\end{array}$ & $\begin{array}{l}\text { Scale of } \\
\text { impact }\end{array}$ \\
\hline \multicolumn{5}{|l|}{ Meteorological changes } \\
\hline Vertical wind (cooling rate) fluctuations ${ }^{\mathrm{a}}$ & Not known & More and smaller ice crystals ${ }^{\mathrm{b}}$ & High & Local \\
\hline Relative humidity & Constant & Constant coverage & High & Regional \\
\hline Tropopause altitude & Increase & Less ice water content ${ }^{\mathrm{c}}$ & High & Regional \\
\hline \multicolumn{5}{|l|}{ Aerosol-induced changes } \\
\hline Supercooled aerosols & Increase $^{\mathrm{d}}$ & Moderate changes & Low & Local \\
\hline Dust & Increase $^{\mathrm{d}}$ & Depending on dynamical forcing ${ }^{\mathrm{e}}$ & $\operatorname{High}^{\mathrm{f}}$ & Local \\
\hline Black carbon & Increase $^{\mathrm{d}}$ & Depending on dynamical forcing ${ }^{\mathrm{e}}$ & Low & Local \\
\hline \multicolumn{5}{|l|}{ Cloud-induced changes } \\
\hline Contrail cirrus & Increase & Lower coverage $^{\mathrm{g}}$ & Medium $^{\mathrm{h}}$ & Regional \\
\hline Deep convection & Not known & Higher coverage $^{\mathrm{b}}$ & $\operatorname{High}^{\mathrm{i}}$ & Regional \\
\hline
\end{tabular}

In judging natural cirrus changes, it is assumed that the magnitude of each controlling factor increases independently. Water vapor, temperature, and vertical wind speed influence the large-scale distribution and level of ice supersaturation supporting cirrus formation and persistence. Vertical air motion (temperature) variability on small-scales affects the local supersaturation around ice-nucleating aerosol particles and therefore ice nucleation. Aqueous particles are mainly composed of sulfates, nitrates, ammonium, and organic compounds, many of which arise from air pollution. They constitute the vast majority of ubiquitous background particles capable of homogeneous freezing. Solid particles include black carbon particles deriving from a number of combustion-related anthropogenic activities as well as mineral dust originating from desert regions and soil dust particles originating mainly from and water use. Solid particles, a small subset of the atmospheric aerosol, are expected to be internally mixed with other species either due to co-emission or atmospheric chemical processing, which affects their propensity to form ice by heterogeneous nucleation. Contrail cirrus generated by jet aircraft enhance cloudiness and change natural cirrus by altering the moisture and heat budget on regional scales. Deep convective clouds affect cirrus by upper tropospheric moistening and by injection of frozen condensate

${ }^{a}$ Due to mesoscale gravity waves

${ }^{\mathrm{b}}$ For increased strength of the assumed change

${ }^{\mathrm{c}}$ For cirrus forming closer to the tropopause

${ }^{\mathrm{d}}$ Depending on demographic, social, economic, technological, and environmental developments

${ }^{\mathrm{e}}$ More and smaller (fewer and larger) ice crystals for strong (weak) forcing

${ }^{\mathrm{f}}$ For some uncoated types of dust particles

${ }^{g}$ Total cirrus coverage increases

${ }^{\mathrm{h}}$ At midlatitudes in the northern hemisphere

${ }^{\mathrm{i}}$ At low latitudes

and the chemical composition of residual particles in single ice crystals using mass spectrometry. Such measurements are at times carried out in conjunction with ancillary measurements of moisture, temperature (to infer ice supersaturation), and vertical wind speed. Most of the past in situ measurements suffered from multiple artificial counts of small ice crystals [22]. Copious small ice crystals can result from shattering of larger crystals on aircraft instrument apertures. Recent advances in ice cloud particle instrument measurements removed much of the past uncertainty that strongly limited the ability to detect anthropogenic effects on cirrus [23]. Nonetheless, untangling effects of changes in dynamical forcing and aerosol on cirrus properties remains challenging [24].

There is a paucity of atmospheric data providing quantitative relationships between anthropogenic influences on aerosols, ice cloud variables (in particular ice crystal number concentrations), synoptic control, vertical wind speed, and local supersaturation variability. It is not straightforward to infer ice nucleation mechanisms from atmospheric measurements for several reasons. Satellite observations do not capture the local supersaturation that is relevant for ice nucleation. Due to the small scales and transient nature of nucleating cells and the high speed of airborne measurement platforms, freshly nucleated ice crystals are poorly sampled, so that the ice formation stage is likely underrepresented in aircraft data sets. Moreover, sedimentation and turbulent mixing reduce the number concentration of pristine ice crystals prior to detection. An agreement by at best of a factor of two between ice crystal concentrations measured in situ with independent techniques [25] makes it difficult to disentangle effects of aerosols and dynamical forcing. Sampling the composition of cirrus ice crystal residuals by itself does not provide direct causal 
relationships to their IN activity. The stochastic nature of small-scale ice cloud forcing calls for comparison of observations with ensemble simulations capable of providing cloud property statistics. A direct comparison of deterministic cloud models with observational case studies can be misleading, except in wave clouds wherein a stationary nucleation zone can be sampled and compared to model predictions [26].

Process-based models are used to test atmospheric implications of proposed theoretical concepts and might allow or facilitate the interpretation of laboratory and field observations. They are viable tools to build parameterization schemes used to represent effects of aerosols and clouds, including interactions among themselves and with the meteorological situation or with radiation, in global models that are not capable of resolving such effects explicitly. Large-scale models are needed to explore the global consequences of local or regional climate forcing mechanisms and ultimately allow to quantify measures of their impact on climate, such as their instantaneous radiative forcing, changes in the hydrological cycle, or temperature changes on long time horizons. Bridging the scale gap between process models and global models by means of parameterization development is a great scientific challenge.

\section{Anthropogenic Impacts on Cirrus}

This section reviews recent observational and climate model studies investigating cirrus changes and possible links to anthropogenic activities. Many studies focus on aerosol effects on cirrus.

\section{Observational Evidence}

Infrared sounding has been used to examine large-scale icesupersaturated regions in the upper troposphere from space [27]. These satellite data show hemispheric differences in supersaturation, with higher levels in the Southern Hemisphere attributed to a higher temperature variance there. Moreover, the northeastern Pacific and the more polluted North Atlantic have similar frequencies of supersaturation, supporting the notion of a dynamical rather than a microphysical (via icenucleating aerosol particles) control. Aircraft measurements suggested that hemispheric differences in microphysical properties of mid-latitude cirrus clouds lie within a wide range of variability - those differences could not be ascribed unambiguously to differences in aerosol properties [28]. Lidar measurements yielded inconclusive results concerning a possible impact of anthropogenic aerosols on properties of tropical cirrus, presumably because the clouds evolved in different meteorological conditions [29]. It is often difficult to relate observed changes in cloud properties uniquely to either changes in aerosols or changes in the dynamical forcing, since ice phase processes respond sensitively to even small changes in certain ambient conditions.

Particulate organics partitioning poorly into the ice phase have been detected in extratropical locations [30]. They are underrepresented in ice crystal residues likely owing to disparate water vapor uptake between organic and inorganic liquid particles [31]. Mixtures of sulfate and organic particles dominated the composition of aerosol particles in the TTL [32]. It is possible that the formation of IN composed of amorphous semisolids and glasses from organic liquids occurs throughout the troposphere more often than previously thought [33]. It has been proposed that organic aerosols can act as efficient ice nuclei in the cold upper troposphere due to their highly viscous ("glassy") nature [34]. In situ observations revealed TTL cirrus with low and high ice crystal number concentrations [35]. The observed narrow layers containing high ice crystal concentrations were likely transient. In certain conditions, cloud radiative heating may stabilize TTL cirrus in the absence of an external forcing [36]. Along with nucleation, mixing, and sedimentation, mesoscale air motion and radiative processes impact the dehydration potential of subvisible cirrus.

Mineral dust particles have possibly caused ice nucleation in almost all of the cirrus clouds probed in field missions located in convectively influenced continental areas at northern low latitudes [37]. However, heterogeneous ice nucleation does not necessarily prevent homogeneous freezing from occurring and the latter will dominate ice number concentrations at prevailing high cooling rates if it occurs. An analysis of conjoined relative humidity and cloud data taken in the field provided evidence for the prevalence of homogeneous freezing in southern midlatitudes and hinted at the existence of heterogeneous ice nucleation in cirrus in parts of the more polluted northern midlatitudes, but did not suggest that cirrus in the latter region formed exclusively on IN [38]. The effect of mesoscale gravity waves on vertical wind statistics combined with homogeneous aerosol freezing yielded fair agreement between simulated ice number frequency distributions and those observed in synoptically forced cirrus at northern midlatitudes [25].

In the latter two studies, it was found that the addition of a small number of IN to liquid particles competed with homogeneous freezing but did not prevent it from occurring. Rather, adding few IN to the background aerosol can lower total ice crystal number concentrations for a given dynamical forcing. This mechanism has been coined "negative" Twomey effect [39] - the opposite effect that an increase in the number of chemically uniform cloud condensation nuclei has on liquid cloud droplet number. One observational study suggested that IN played only a limited role in affecting ice formation in the tops of deep convective clouds [40], likely due the onset of homogeneous freezing [41]. Data collected in upper anvil regions of mid-latitude thunderstorms hint at a prevalence of liquid cloud droplets as the main sources of frozen condensate 
[42]. Characterization of the microphysical and optical properties of young anvil cirrus and the statistics of updraft speeds in deep convective outflow require further scrutiny, complementing ongoing efforts to understand the macrophysical response of high cloudiness to climate warming [43].

\section{Climate Model Studies}

Studies of anthropogenic impacts via aerosol indirect effects on cirrus and contrail-induced cloudiness have mostly been carried out with GCMs. Early GCM simulations with parameterized cirrus formation have been based on the homogeneous aerosol freezing process that is relatively well understood on a process level and can therefore be parameterized with confidence when predicted updraft speeds are corrected for unresolved variability [44]. Some uncertainty in predicted homogeneous ice formation is introduced by poorly known number size distributions and chemical composition of upper tropospheric aerosol particles [45].

GCM studies suggested the possibility that increases in anthropogenic sulfate aerosol and black carbon particles (or soot) may change ice crystal number concentrations in cirrus clouds [46]. The magnitude of the cirrus-induced forcing was predicted to be comparable to the aerosol forcing exerted by warm clouds; its sign could not be ascertained. One GCM study used different ice nucleation parameterizations [47]. Simulated indirect aerosol effects due to rising sulfur emissions have been confirmed, but occur via different mechanisms in different models. Using updated soot ice nucleation efficiencies, the indirect effect of soot particles on cirrus was found to be small and statistically insignificant, a finding in line with laboratory and field measurements [48]. The poor representation of cooling rate variability feeding cirrus ice nucleation parameterizations in large-scale models renders results with regard to first ice formation uncertain [49].

One GCM study investigated potential effects of IN on cirrus by introducing separate cloud ice modes representing four ice crystal sources: liquid particles, mineral dust, soot, and preexisting ice crystals, e.g., from glaciating liquid water clouds [50]. With this methodology, different properties of individual ice modes could be simulated extending the traditional approach of merging ice crystals from all particle sources into a single mode. Ice crystal number concentrations in cirrus were reduced by the action of IN, emphasizing the importance of a competition for condensable water vapor between various ice nucleation modes during freezing events $[51,52]$. Other effects of IN were to reduce upper tropospheric water vapor concentration and cirrus ice water content slightly due to efficient ice crystal sedimentation.

The same multiple ice mode scheme was used to study aerosol-cirrus interactions involving sulfates, bare and coated dust particles, and frozen liquid cloud droplets injected at cirrus levels [53]. Increases in sulfur emissions favor homogeneous nucleation of liquid aerosols on the one hand, but may dampen heterogeneous nucleation by coating IN with soluble matter [54] on the other. Preexisting ice affects cirrus microphysical and radiative properties mainly in the tropics, while dust IN exert a notable impact on cirrus formation at northern midlatitudes [50]. The former finding rests on the presumption that ice is already present in the same location within a GCM grid cell where new ice formation takes place; this is not resolved in low-resolution models.

Atmospheric ammonia concentrations are strongly affected by the use of nitrogen-based fertilizers and release through livestock. One study pointed at a link between anthropogenic ammonia emissions and cirrus formation through the formation of crystalline, ammoniated sulfate particles acting as IN [55]. One GCM study inferred a net cooling due to cirrus changes in idealized scenarios with prescribed concentrations and assumed nucleation properties of such IN that were allowed to compete for ice formation with pure sulfates and mineral dust particles. The formation pathways of solid ammonium sulfate particles depend in complex ways on the small-scale evolution of relative humidity [56]. Those pathways were not resolved in the GCM study.

\section{Aircraft Effects on Cirrus}

Jet aircraft emit a significant number of fine soot particles in the upper troposphere. Regarding the potential impact of aircraft-emitted soot particles on cirrus, a considerably smaller perturbation was simulated by [50] than by an earlier study [57], even though favorable assumptions regarding ice-active fraction and freezing relative humidity of aviation soot were used. One reason for this difference may be the weak dynamical cloud forcing imposed in the earlier study favoring heterogeneous over homogeneous ice nucleation. Another GCM study predicted significant cirrus forcing when assuming aircraft soot particles to be efficient IN that are preconditioned in contrails [45]. The sign of the simulated forcing varied depending on assumptions on how cirrus clouds form in the background atmosphere.

Persistent line-shaped contrails evolve into irregularly shaped cirrus clouds in large-scale, ice-supersaturated upper tropospheric areas. Together, they are the most easily perceived evidence of perturbed high clouds. Contrail cirrus clouds do not merely replace natural cirrus, but exhibit different microphysical and optical properties due the presence of numerous small ice crystals generated in the contrail formation stage that unfolds close behind individual aircraft engines. One GCM represents contrail cirrus as a separate class of cloud evolving in parameterized ice-supersaturated areas and interacting with natural clouds (mostly cirrus) and the moisture field [58]. This methodological step forward not only enabled the simulation of contrail cirrus life cycle and the first 
model-based estimate of their net radiative forcing but also suggested a negative (short-term) feedback due to a reduction in natural cloudiness due to consumption of water vapor by contrail cirrus that would otherwise be available for formation and growth of other cirrus particles. Reducing soot (i.e., contrail source) particle emissions from aircraft jet engines may be viewed as a root-level solution alleviating aircraft-induced cloud impacts on climate [59].

\section{Geoengineering of Cirrus}

Many GCM studies deal with climate engineering of cirrusthe intentional large-scale manipulation of OLR to counteract anthropogenic climate change [60] - as a tangible alternative to albedo modification and carbon dioxide removal [61].

The idea to deliberately modify cirrus clouds by injecting very efficient IN in cirrus formation regions - thus directly counteracting greenhouse gas warming by increasing OLR and surface cooling - was proposed together with a discussion of apparent advantages and drawbacks of cirrus seeding [62]. Seeding is regarded to be most effective at high latitudes, where cirrus induce a large net warming effect and tend to have large coverage. The idea is based on the "negative" Twomey effect (seeded IN outcompete natural particles for water vapor during ice formation) ultimately leading to reduced cirrus coverage and increased OLR. Subsequent GCM simulations hinted at a significant potential of climate engineering of cirrus to affect circulation and rainfall. The envisaged cooling effect was confirmed in a climate response analysis. It was found that overseeding cirrus would amplify global warming $[63,64]$. The spatially non-homogeneous forcing induces circulation changes with the risk of side effects in remote unseeded regions [65, 66]. Another study found that the cooling resulting from seeding of mid- and high-latitude cirrus is accompanied by only a modest reduction in rainfall [67]. Combining "thinning" of cirrus with projected $\mathrm{CO}_{2}$ increases in multidecadal climate simulations led to an enhancement of the hydrological cycle [68].

Two recent GCM studies did not confirm some of these findings and suggested that global uniform seeding does not lead to significant cooling [69, 70]. Disregarding feedbacks due to upper tropospheric temperature and humidity changes, an off-line study showed that climate engineering with stratospheric sulfate aerosol particles that are subsequently transported into the troposphere is unlikely to have large microphysical effects on mean cirrus radiative forcing [71].

\section{Challenges in the Model Representation of Cirrus}

Robust prediction of changes in climate that result from changes in cirrus clouds relies to a large extent on the improvement of the microphysical and macrophysical representation of cirrus in global models.

\section{Understanding Ice Formation in Cirrus}

There are many aspects to the problem of parameterization of microphysical processes related to clouds and precipitation in numerical models of the atmosphere [72]. Simulating the climate forcing from cirrus clouds is challenging in part due to an incomplete understanding of ice cloud formation mechanisms related to IN [73]. There is a striking lack of measurements of heterogeneous ice nucleation rate coefficients for relevant types of IN for use in process models and parameterizations. The effect of small ice crystals, stemming from nucleation, on cirrus cloud amount and radiative forcing predicted by some GCMs via changes in cloud ice sedimentation is substantial [74]. The development of two-moment parameterizations for cirrus ice crystal number and mass concentrations [44, 50, 75-78] and more complex sectional schemes [79] provided a basis upon which ice nucleation and aerosol-cirrus interactions could be simulated with global models. Besides requiring parameters describing properties of ice-nucleating particle populations, such parameterizations need to be driven by local vertical wind speeds or associated temperature perturbations. Internal gravity waves excite an ever-present background spectrum of rapid cooling and heating rates unresolved in GCMs yet crucial for ice nucleation. The full range of mesoscale variability in vertical wind speeds relevant for ice nucleation is only crudely parameterized in GCMs and effects of smaller scales have not been systematically explored. Some GCMs use explicit parameterizations of orographic cirrus clouds that are known to form over certain mountainous terrain because the associated portion of the wave spectrum was not represented in the model and hence prevented their formation [80, 81].

It is essential to raise fundamental issues about the dynamical forcing, while at the same time recognizing that atmospheric ice crystals may nucleate on a plethora of aerosol particles with vastly different ice-forming properties. Indirect evidence from field observations supports the existence of a competition between homogeneous and heterogeneous ice nucleation processes in cirrus [82]. In this regard, three issues are crucial: (i) IN rarely exceed number concentrations of about $50 / \mathrm{L}$ in the background upper troposphere (fewer in the TTL) and nucleate ice at lower supersaturations than liquid aerosol particles; (ii) gravity waves generate broad distributions of vertical wind speeds with mean updraft speeds (cooling rates) of some $10 \mathrm{~cm} / \mathrm{s}(-3.6 \mathrm{~K} / \mathrm{h})$; (iii) ice nucleation is controlled by local supersaturation, i.e., in the proximity of icenucleating particles, whereby already existing ice crystals affect the nucleation process through their ability to deposit water vapor and thereby quench supersaturation fluctuations. Small-scale fluctuations of supersaturation do not only critically affect the ice number through nucleation but may also 
broaden ice crystal size distributions in thin cirrus and therefore enhance ice mass fluxes due to sedimentation [83].

Homogeneous freezing produces an upper limit ice crystal number concentration, $n_{\text {ice, }}$, at any given updraft speed, $w$. This relationship, $n_{\text {ice }}(w)$, is displayed in Fig. 1 for conditions at midlatitudes and in the TTL as solid curves. The critical updraft speeds for the onset of homogeneous freezing in the presence of IN are displayed as a function of the IN number concentration, $n_{\mathrm{IN}}$, as curves with broken line styles. Up to values $w=w_{\mathrm{cr}}, \mathrm{IN}$ may prevent homogeneous freezing from occurring by

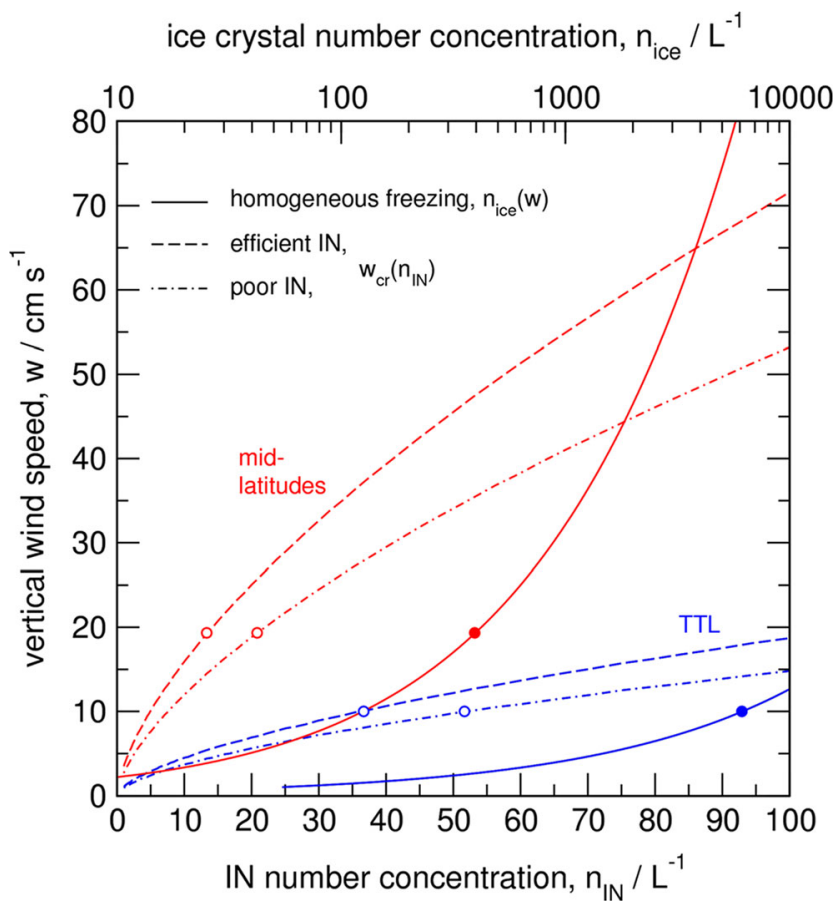

Fig. 1 Competition between homogeneous and heterogeneous ice nucleation. Colored curves are computed for conditions at midlatitudes (red: air pressure $250 \mathrm{hPa}$, air temperature $220 \mathrm{~K}$ ) and the TTL (blue: $100 \mathrm{hPa}, 190 \mathrm{~K}$ ) using a GCM parameterization scheme for cirrus formation [51]. The range of constant vertical wind (updraft) speeds, $w$, is typical for observed gravity-wave driven mesoscale variability. In GCMs, subgrid-scale updraft speeds are usually estimated from the models' turbulence kinetic energy, a poor representation of the real variability. The range of IN number concentrations, $n_{\mathrm{IN}}$, is typical for the background free troposphere. IN concentrations are diagnosed in GCMs based on simulated aerosol particle properties, prescribing heterogeneous ice nucleation behavior. Solid curves display ice crystal number concentrations, $n_{\text {ice, }}$, produced in the absence of IN by homogeneous freezing at any given $w$. Homogeneous freezing is not limited by the number of liquid aerosol particles much exceeding $n_{\mathrm{IN}}$. Dashed and dot-dashed curves denote the values $w_{\mathrm{cr}}$ below which homogeneous freezing does not occur for given number concentration, $n_{\mathrm{IN}}$, of efficient or poor IN. Idealized efficient (poor) IN are defined here to nucleate ice sharply at relative humidity over ice $\mathrm{RHI}=110 \%(140 \%)$, below homogeneous freezing thresholds (150-160\%). Sharp ice nucleation thresholds are an idealization for many IN types. The associated critical updraft speeds, $w_{\mathrm{cr}}$, are upper limits, since the parameterization does not include sedimentation of early nucleated ice crystals. Those values could also change in situations with rapidly changing updraft speeds quenching the supersaturation - the supersaturation sink due to vapor deposition on early nucleated ice crystals is strong enough to counteract the supersaturation increase due to cooling induced by the sustained updraft. For $w>w_{\mathrm{cr}}$, all IN form ice and liquid particles also freeze, although fewer than without preexisting ice from the IN. This means that the entire range from $n_{\mathrm{IN}}$ up to $n_{\text {ice }}$ can result from the competition between the two nucleation modes, indicated by open and filled circles. For instance, at $20 \mathrm{~cm} / \mathrm{s}$, pure heterogeneous nucleation occurs for $n_{\mathrm{IN}}<10(20) / \mathrm{L}$ at midlatitudes and at $10 \mathrm{~cm} / \mathrm{s}$ for $n_{\mathrm{IN}}$ $<35(50) / \mathrm{L}$ in the TTL for efficient (poor) IN, as indicated by open circles. Upon increasing $w$, the competition between the two modes becomes inefficient; ice crystal number concentrations gradually increase and may reach values up to $n_{\text {ice }}=400$ (6000)/L (solid circles), which are only rarely observed.

Despite a number of simplifications of the underlying model, this suggests a significant potential for IN to lower $n_{\text {ice }}$, or suppress homogeneous freezing altogether, in regions of the upper troposphere where their concentrations exceed some 10/L. This happens for updraft speeds $>10 \mathrm{~cm} / \mathrm{s}$ which are commonly observed. The transition between pure homogeneous and heterogeneous ice nucleation occurs over a large range of IN number concentrations. In nature, vertical wind speeds evolve highly irregularly along air parcel trajectories quenching nucleation events; turbulence dilutes the nucleating cells and may affect nucleation by entrainment-mixing; preexisting ice crystals from other sources may be present preventing nucleation from occurring; IN may nucleate over a broad range of supersaturation; early formed ice crystals may fall out of the nucleation layer making cirrus less sensitive to the presence of relatively few IN. All of these processes tend to reduce ice crystal number concentrations during or right after nucleation occurred and need to be considered in future cirrus ice nucleation parameterizations.

The perhaps most extensive data set on thin cirrus formation and development was taken in the TTL [13, 84]. Meteorological and microphysical variables have been observed using in situ and satellite observations and analyzed with a Lagrangian column model constrained as much as possible to infer details of ice formation processes. Mesoscale high frequency vertical air motion variability along a large ensemble of air trajectories has been constrained by data from super-pressure balloon observations. The authors conjectured that processes other than the currently accepted homogeneous aerosol freezing model applied for chemically uniform aerosol composition are required to reconcile simulated and observed ice crystal number concentrations. The sensitivity of TTL cirrus extinction, ice water content statistics, and simulated occurrence frequencies (regional and height distributions) of TTL cirrus to IN abundance was weak. Including numerous IN (>100/L) improved the comparison with observed ice concentrations but could not explain observed high ice supersaturations. 


\section{Non-equilibrium Ice Cloud Physics in GCMs}

The formation of cirrus clouds is different to that of liquid clouds. Contrary to cirrus, liquid clouds require only very small supersaturation over liquid water to form and persist at liquid water saturation. A probability distribution (PDF) of total water mass along with the liquid water vapor saturation pressure can thus be used to diagnose cloud-free and cloudy areas, i.e., cloud coverage, as well as liquid water mass. For cirrus, icesupersaturated areas extend over a substantial range of relative humidity and may or may not be covered with cloud. As cirrus form at substantial ice supersaturation and drive the relative humidity towards ice saturation on time scales that may well exceed a GCM time step (as for most TTL cirrus containing only few small ice crystals), cirrus cloud coverage should not be estimated in the same way as for liquid clouds in large-scale models [85]. Importantly, resolving in-cloud ice supersaturation is a prerequisite for simulating aerosol indirect effects on cirrus. However, care must be taken to track ice supersaturation, cirrus coverage, ice crystal number, and ice water content consistently.

A cirrus cloud will form in air that cools and locally surpasses a given ice nucleation threshold; the ice phase will be thermodynamically stable as long as the air remains at least ice-saturated. Saturation adjustment-any water vapor above saturation is instantaneously converted to cloud water-as a common approximation employed to simulate liquid clouds in GCMs, should not be applied to cirrus. For sustained dynamical forcing and ignoring water vapor deposition, for simplicity, the fractional cirrus coverage in a model grid box describes a hysteresis with evolving relative humidity (Fig. 2); hence, ice cloud coverage cannot simply be diagnosed but should be predicted. To introduce correct ice physics in a PDF cloud parameterization framework [86], a prognostic variable has to be introduced replacing the saturation vapor pressure and carrying the memory of the history of cirrus ice formation. This new variable must contain information on both, the forcing (subgrid-scale temperature variability) and the ice nucleation and growth processes. This will ultimately allow a selfconsistent prediction of cirrus ice crystal number, ice water content, and coverage along with the coupling to meteorological processes affecting higher PDF moments. Further challenges in the development of such new generation PDF-based cloud schemes for low-resolution models might include the consistent treatment of cirrus from multiple sources within a grid box and the interaction of cirrus with lower level liquid clouds, i.e., the mixed-phase cloud regime.

\section{Further Scientific Challenges and Research Opportunities}

To study the full range of anthropogenic impacts on cirrus, climate model simulations require aerosol-cirrus interactions

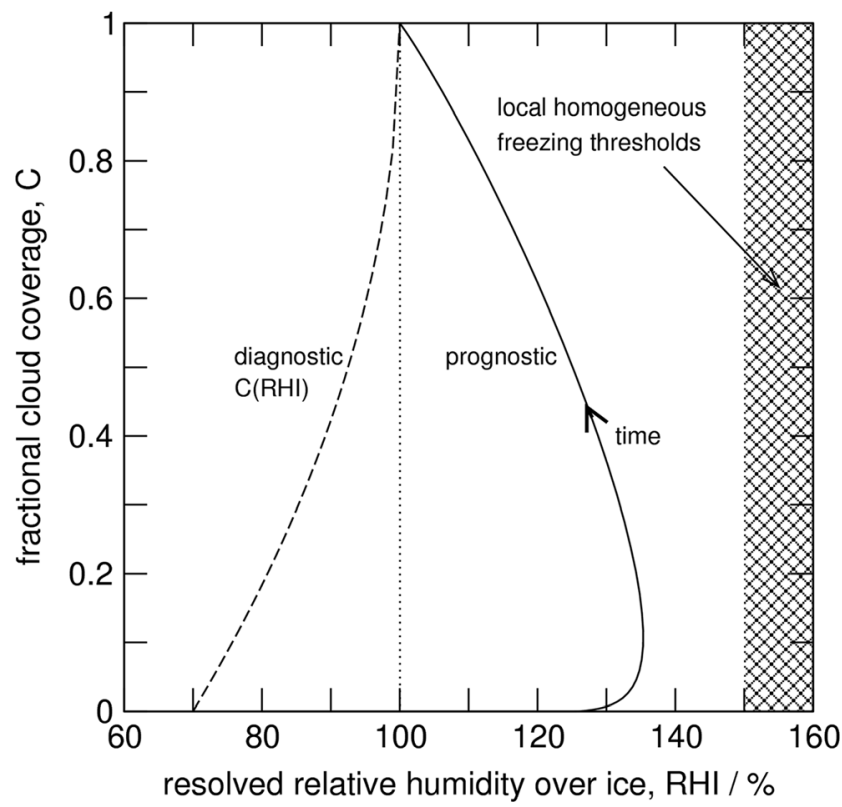

Fig. 2 Treatment of fractional cloud coverage in models with coarse spatial resolution. Diagnostic cloud coverage, $C$, as a function of resolved (grid scale) relative humidity over ice, $R H I$, in a continuously nucleating ice-supersaturated area (RHI $>100 \%$ ). For cirrus, a prognostic treatment tracks the time evolution of $\mathrm{C}$. This requires knowledge about the ice nucleation process, its local dynamical forcing, and the assumed shape of the total water PDF underlying the models' cloud scheme. In both cases, the grid cell is fully covered $(C=1)$ in grid mean ice-saturated conditions $(\mathrm{RHI}=100 \%)$. A range of local threshold RHI values for homogeneous aerosol freezing in cirrus is indicated (cross-hatched area). Areas within the grid cell wherein the ice supersaturation surpasses those thresholds increase with rising RHI

to be represented. However, despite considerable progress, those interactions constitute a large uncertainty in terms of their radiative effects [87]. Cloud microphysical and associated dynamical processes evolve on subgrid scales and will not be explicitly resolved in global climate models in the foreseeable future. There are many reasons why uncertainties in cirrus properties and evolution matter. Here, two interconnected issues have been discussed: the microphysical (cirrus formation) and macrophysical (cirrus coverage) representation in GCM cloud schemes.

While I have focused on the cirrus parameterization issue for brevity, the list of challenges is clearly longer. In particular, investigations of two-way interactions between cloud-scale processes and larger-scale forcings hold rich opportunities for future research. In efforts to better understand links between cirrus and the large-scale flow, it may be beneficial in GCMs to treat cirrus from detrained convection separately from cirrus that form in situ, as they differ in their sources, microphysical/optical properties, and radiative impact. Based on measurements that provide collocated multi-scale dynamical and local microphysical information, crucial ice phase processes and their controlling variables that are best suited for evaluation of models need to be identified. Strategies to probe ice-nucleating cells under similar meteorological 
conditions and to analyze the life cycle of cirrus - particularly anvil cirrus - along with changes in their spatial coverage and physical properties should be devised.

Modeling of cirrus formation from aerosols in GCMs should be based on robust parameterizations for heterogeneous ice nucleation rate coefficients that are currently not available to simulate the competition between multiple nucleation modes with confidence. Those simulations also need to include details of the Lagrangian temporal evolution of smallscale cooling rates, the vertical fine structure of water vapor concentrations, and effects of ice crystal sedimentation [12, 88-91], all influencing supersaturation development within ice clouds. Water vapor deposition coefficients on cirrus ice crystals depend on supersaturation and determine the shapes of pristine ice crystals, but are only crudely parameterized in cirrus models taking constant values. This affects ice crystal growth rates in maturing cirrus to an unknown degree. Ice crystal shapes in turn affect their fall speeds and growth rates [92]; the impact of this process link also needs to be scrutinized. Moreover, the representation of optical properties of ice clouds in GCM-based radiative transfer parameterizations is poor due partly to the fact that individual ice crystals have non-spherical shapes and exhibit submicron-scale surface roughness $[93,94]$. This also poses a challenge for devising retrieval algorithms for remote sensing. The frequent occurrence of shallow ice-supersaturated layers, with vertical extensions much below vertical resolutions of satellite sensors, renders the examination of the composition and vertical structure of high ice clouds in layered cloud systems even more challenging [95]. However, space-borne observations are required to make headway in understanding the life cycle and feedback of high-level clouds and to better evaluate GCMs.

Uncertainties in climate predictions arise also due to uncertainties in large-scale circulation changes resulting from high cloud processes [96]. The tops of high clouds are observed to rise in response to global warming [97]. The stratospheric Brewer-Dobson circulation leaves a fingerprint on TTL cloudiness [98]. Likewise, in addition to the meteorological and cloud changes summarized in Table 1, the Quasi-Biennial Oscillation and the El Niño Southern Oscillation affect occurrence frequencies of TTL clouds [99]. These large-scale variability patterns respond to temperature changes in a changing climate, as does convective precipitation due to selforganization of small-scale convective events into larger cloud clusters [100].

To produce robust predictions of cirrus evolution in a changing climate, a sound macrophysical representation of cirrus in GCMs is crucial, besides necessary improvements in the microphysical and radiative parameterizations. Conventional diagnostic methods in GCMs appropriate for liquid clouds lack essential physics when applied to ice clouds. Advanced satellite remote sensing capabilities create new opportunities for assessing and synthesizing findings from such measurements for model development and evaluation of (optically thin) cirrus clouds [101, 102]. Combining remote sensing information with reanalysis data allows connections to be made between bulk cirrus cloud properties and the large-scale dynamical regimes in which anvil cirrus form and evolve [103]. Due to the link between of convective detrainment and anvil cirrus formation, it is necessary to improve parameterizations of deep convection used in GCMs, especially regarding frequency, location, and strength of upper tropospheric mass fluxes and their link to detrainment of frozen condensate $[104,105]$. The global distribution of number concentrations of efficient IN, the representation of heterogeneous ice nucleation, and small-scale vertical air motion variability need to be better understood on the process level and then improved in GCMs.

\section{Conclusions}

Cirrus clouds will continue to play important roles in a future climate perturbed by anthropogenic activities. Whether the climatic impact of cirrus grows or diminishes in importance remains elusive, as this is influenced in numerous and intertwined ways by: (i) changes in upper tropospheric moisture, temperature, and vertical winds; (ii) changes in location, abundance, and ice-forming properties of atmospheric aerosols; and (iii) changes in occurrence frequency, extent, and properties of other clouds. In view of projected increases in air traffic volume, contrail cirrus become increasingly more important in enhancing and modifying high cloudiness. Changes in the microphysical and optical properties of cirrus may affect responses to climate warming of other tropospheric cloud types along with their propensity to affect the Earth's energy budget and to induce surface precipitation. Those changes in low cloud properties and convective activity in turn affect cirrus.

Composition and physical properties of aerosols in the tropopause region are influenced by surface air pollution [106, 107]. Changes in the number and size of supercooled aerosol particles are unlikely to cause large effects on microphysical and optical properties of cirrus because the homogeneous freezing process is rather insensitive to details of the size distribution of freezing particles in conditions of typically strong dynamical forcing of ice nucleation. Organic matter in liquid aerosol particles partitions poorly in the ice phase. Overall, anthropogenic activities altering the upper tropospheric liquid aerosol budget are not expected to cause significant cirrus changes. Those changes, if they occur, could easily be masked by future changes in large-scale cloud formation conditions and local dynamical forcings of ice nucleation.

In regions where dust particles are sufficiently abundant, heterogeneous ice nucleation may compete with ubiquitous homogeneous freezing in non-convective cirrus formation. 
The main resulting effect-reduced total ice crystal number concentrations-depends crucially on small-scale cooling rates, the number concentration of IN, and details of their ice-nucleating properties. The latter are virtually unconstrained by measurements. Some climate models have begun to resolve a range of composition-dependent ice nucleation efficiencies of dust particles from various source regions. A large fraction of atmospheric black carbon concentrations is due to anthropogenic activities [108]; however, field observations have not revealed a significant atmospheric impact on cirrus. Progress in airborne instrumentation yields more accurate ice number concentrations better constraining nucleation processes.

DeMott et al. [19] have a good point stating: "[...] it appears just as important, for the accurate representation of cloud forcing, to properly simulate the lack of available IN as it is to simulate the presence of IN." Measuring systems for atmospheric IN begin to meet the needs for studies of aerosol effects on ice-containing clouds [109]. This progress is required since evidence of IN effects on cirrus is largely based on inference. Substantial progress has been made on the process level constraining aerosol properties and dynamical forcing in the TTL - in one of the least accessible regions in the atmosphere. IN may provide a clue to resolve pending uncertainties regarding ice formation in subvisible cirrus. Almost unexplored territories include aerosol particles with unusual freezing behavior and micro-scale turbulence effects on ice nucleation.

The wide range of partly controversial climate model results regarding aerosol-cirrus interactions and the apparent inability to constrain background (unperturbed) cirrus formation scenarios in GCMs reflect: (i) uncertainties in abundance (emission source strengths and transport and removal pathways) and ice-nucleation efficiency (altered through atmospheric chemical processing) of the various IN types; and (ii) unresolved variability in relative humidity and dynamical forcing driving ice nucleation parameterizations. GCM studies have not led to a consensus of whether seeding cirrus with efficient IN is a viable climate intervention technique. Potential pitfalls attendant with cirrus seeding have been identified: the risk of adverse side effects on circulation and precipitation and the need to carefully dose the number concentration of seeding nuclei to make cirrus "thinning" effective. If cirrus thinning should be considered a viable climate intervention strategy, then further research is needed comprising modeling from the cloud to the global scale, besides more detailed considerations of deployment strategies, seeding particle types, and delivery systems.

Significant advances sometimes require conceptual changes in approach and cannot be achieved simply by continuing conventional research avenues. The complexity of the problems at hand calls for model hierarchies, including applications of simplified, conceptual models and combinations of various observational methods, including laboratory studies. An integrative analysis framework proposed to make headway in studying warm cloud systems [110] - balancing research into microphysical detail resting on low-order observational constraints with exploration of high-order constraints arising from emergent properties of the highly complex aerosol-cloud-radiation system - may serve as a viable conceptual approach to quantify the radiative effect of cirrus with greater confidence. I offer this initial view on cirrus research in the hope of furthering the dialogue in a diverse research community and close with a quote attributed to Niels Bohr: "It is difficult to make predictions, especially about the future."

Acknowledgments I am grateful to Dave Fahey, Eric Jensen, and Dan Murphy for helpful comments and suggestions on early manuscript versions. I thank Graham Feingold, Karl Froyd, Karen Rosenlof, and Pengfei $\mathrm{Yu}$ for fruitful discussions of issues addressed here. Funding was provided by a CIRES (Cooperative Institute for Research in Environmental Sciences) Sabbatical Visiting Fellowship and by DLR.

\section{Compliance with Ethical Standards}

Conflict of Interest The author has no financial or personal relationships with any third party whose interests could be influenced by the article's content.

\section{Glossary}

GCM General circulation model

IN (Heterogeneous) ice nuclei

OLR Outgoing longwave radiation

PDF Probability density function

TTL Tropical tropopause layer

Open Access This article is distributed under the terms of the Creative Commons Attribution 4.0 International License (http:// creativecommons.org/licenses/by/4.0/), which permits unrestricted use, distribution, and reproduction in any medium, provided you give appropriate credit to the original author(s) and the source, provide a link to the Creative Commons license, and indicate if changes were made.

\section{References}

1. Stubenrauch CJ, Cros S, Guignard A, Lamquin N. A 6-year global cloud climatology from the Atmospheric InfraRed Sounder AIRS and a statistical analysis in synergy with CALIPSO and CloudSat. Atmos Chem Phys. 2010;10:7197-214.

2. Stephens GL, van den Heever S, Pakula L. Radiative-convective feedbacks in idealized states of radiative-convective equilibrium. J Atmos Sci. 2008;65:3899-916.

3. Hong Y, Liu G. The characteristics of ice cloud properties derived from CloudSat and CALIPSO measurements. J Clim. 2015;28: 3880-901.

4. Sanderson BM, Piani C, Ingram WJ, Stone DA, Allen MR. Towards constraining climate sensitivity by linear analysis of feedback patterns in thousands of perturbed-physics GCM 
simulations. Clim Dyn. 2008;30:175-90. doi:10.1007/s00382007-0280-7.

5. Sherwood SC, Bony S, Dufresne J-L. Spread in model climate sensitivity traced to atmospheric convective mixing. Nature. 2014;505:37-42. doi:10.1038/nature12829.

6. Mace GM, Deng M, Soden B, Zipser E. Association of tropical cirrus in the 10-15-km layer with deep convective sources: an observational study combining millimeter radar data and satellite-derived trajectories. J Atmos Sci. 2006;63:480-503.

7. Mauritsen T, Stevens B. Missing iris effect as a possible cause of muted hydrological change and high climate sensitivity in models. Nat Geosci. 2015;8:346-51. doi:10.1038/ngeo2414.

8. Randel WJ, Jensen EJ. Physical processes in the tropical tropopause layer and their roles in a changing climate. Nat Geosci. 2013;6:169-76. doi:10.1038/ngeo1733.

9. Solomon S, Rosenlof KH, Portmann RW, Daniel JS, Davis SM, Sanford TJ, et al. Contributions of stratospheric water vapor to decadal changes in the rate of global warming. Science. 2010;327:1219-23. doi:10.1126/science.1182488.

10. Kahn RH, Gettelman A, Fetzer EJ, Eldering A, Liang CK. Cloudy and clear-sky relative humidity in the upper troposphere observed by the A-train. J Geophys Res. 2009;114:D00H02. doi:10.1029/ 2009JD011738.

11. Lamquin N, Stubenrauch CJ, Gierens K, Burkhardt U, Smit H. A global climatology of upper-tropospheric ice supersaturation occurrence inferred from the Atmospheric Infrared Sounder calibrated by MOZAIC. Atmos Chem Phys. 2012;12:381-405.

12. Kärcher B, Ström J. The roles of dynamical variability and aerosols in cirrus cloud formation. Atmos Chem Phys. 2003;3:823-38.

13. Jensen EJ, Ueyama R, Pfister L, Bui TV, Lawson RP, Woods S, et al. On the susceptibility of cold tropical cirrus to ice nuclei abundance. J Atmos Sci. 2016;73:2245-64. doi:10.1175/JAS-D15-0274.1.

14. Muhlbauer A, Kalesse H, Kollias P. Vertical velocities and turbulence in midlatitude anvil cirrus: a comparison between in situ aircraft measurements and ground-based Doppler cloud radar retrievals. Geophys Res Lett. 2014;41:7814-21. doi:10.1002/ 2014GL062279.

15. Podglajen A, Hertzog A, Plougonven R, Legras B. Lagrangian temperature and vertical velocity fluctuations due to gravity waves in the lower stratosphere. Geophys Res Lett. 2016;43:3543-53. doi:10.1002/2016GL068148.

16. Li Q, Rapp M, Stober G, Chau JL. High-resolution measurements of vertical velocity and their power spectra observed with the MAARSY radar at Andøya, Norway $\left(69.03^{\circ} \mathrm{N}, 16.04^{\circ} \mathrm{E}\right)$. Ann Geophys. 2016;34:1209-29. doi:10.5194/angeo-34-1209-2016.

17. Sheyko BA, Sullivan SC, Morales R, Capps SL, Barahona D, Shi $\mathrm{X}$, et al. Quantifying sensitivities of ice crystal number and sources of ice crystal number variability in CAM 5.1 using the adjoint of a physically based cirrus formation parameterization. J Geophys Res. 2015;120:2834-54. doi:10.1002/2014JD022457.

18. Cziczo DJ, Froyd KD. Sampling the composition of cirrus ice residuals. Atmos Res. 2014;142:15-31. doi:10.1016/j.atmosres. 2013.06.012.

19. DeMott PJ, Prenni AJ, Liu X, Kreidenweis SM, Petters MD, Twohy $\mathrm{CH}$, et al. Predicting global atmospheric ice nuclei distributions and their impacts on climate. Proc Natl Acad Sci U S A. 2010;107:11217-22. doi:10.1073/pnas.0910818107.

20. Jiang JH, Su H, Zhai C, Perun V, Del Genio AD, Nazarenko LS, et al. Evaluation of cloud and water vapor simulations in CMIP5 climate models using NASA "A-Train" satellite observations. J Geophys Res. 2012;117:D14105. doi:10.1029/2011JD017237.

21. DelGenio AD. Representing the sensitivity of convective cloud systems to tropospheric humidity in general circulation models. Surv Geophys. 2012;33:637-56. doi:10.1007/s10712-011-91489.
22. Korolev AV, Emery EF, Strapp JW, Cober SG, Isaac GA, Wasey $\mathrm{M}$, et al. Small ice particle observations in tropospheric clouds: fact or artifact? Airborne Icing Instrumentation Evaluation Experiment. Bull Am Meteorol Soc. 2011;92:967-73. doi:10. 1175/2010BAMS3141.1.

23. Baumgardner D, Avallone L, Bansemer A, Borrmann S, Brown P, Bundke U, et al. In situ, airborne instrumentation — addressing and solving measurement problems in ice clouds. Bull Am Meteorol Soc. 2012;93:ES30-4. doi:10.1175/BAMS-D-11-00123.1.

24. Muhlbauer A, Ackerman TP, Lawson RP, Xie S, Zhang Y. Evaluation of cloud-resolving model simulations of midlatitude cirrus with ARM and A-train observations. J Geophys Res. 2015;120:6597-618. doi:10.1002/2014JD022570.

25. Jensen EJ, Lawson RP, Bergman JW, Pfister L, Bui TP, Schmitt CG. Physical processes controlling ice concentrations in synoptically forced, midlatitude cirrus. J Geophys Res. 2013;118:1-13. doi:10.1002/jgrd.50421.

26. Jensen EJ, Toon OB, Tabazadeh A, Sachse GW, Anderson BE, Chan $\mathrm{KR}$, et al. Ice nucleation processes in upper tropospheric wave-clouds observed during SUCCESS. Geophys Res Lett. 1998;25:1363-6.

27. Gettelman A, Collins WD, Fetzer EJ, Eldering A, Irion FW. Climatology of upper-tropospheric relative humidity from the Atmospheric Infrared Sounder and implications for climate. J Clim. 2006;19:6104-21.

28. Gayet J-F, Shcherbakov V, Mannstein H, Minikin A, Schumann U, Ström J, et al. Microphysical and optical properties of midlatitude cirrus clouds observed in the southern hemisphere during INCA. Q J R Meteorol Soc. 2006;132:2719-48. doi:10.1256/qj. 05.162 .

29. Seifert P, Ansmann A, Müller D, Wandinger U, Althausen D, Heymsfield AJ, et al. Cirrus optical properties observed with lidar, radiosonde, and satellite over the tropical Indian Ocean during the aerosol-polluted northeast and clean maritime southwest monsoon. J Geophys Res. 2007;112:D17205. doi:10.1029/ 2006JD008352.

30. Cziczo DJ, DeMott PJ, Brooks SD, Prenni AJ, Thomson DS, Baumgardner $\mathrm{D}$, et al. Observations of organic species and atmospheric ice formation. Geophys Res Lett. 2004;31:L12116. doi: 10.1029/2004GL019822.

31. Kärcher B, Koop T. The role of organic aerosols in homogeneous ice formation. Atmos Chem Phys. 2005;5:703-14.

32. Froyd KD, Murphy DM, Lawson P, Baumgardner D, Herman RL. Aerosols that form subvisible cirrus at the tropical tropopause. Atmos Chem Phys. 2010;10:209-18.

33. Koop T, Bookhold J, Shiraiwa M, Pöschl U. Glass transition and phase state of organic compounds: dependency on molecular properties and implications for secondary organic aerosols in the atmosphere. Phys Chem Chem Phys. 2011;13:19238-55.

34. Wilson TW, Murray BJ, Wagner R, Möhler O, Saathoff H, Schnaiter M, et al. Glassy aerosols with a range of compositions nucleate ice heterogeneously at cirrus temperatures. Atmos Chem Phys. 2012;12:8611-32.

35. Jensen EJ, Diskin G, Lawson RP, Lance S, Bui TP, Hlavka D, et al. Ice nucleation and dehydration in the tropical tropopause layer. Proc Natl Acad Sci U S A. 2013;110:2041-6. doi:10.1073/pnas. 1217104110.

36. Dinh TP, Durran DR, Ackerman TP. Maintenance of tropical tropopause layer cirrus. J Geophys Res. 2010;115:D02104. doi:10. 1029/2009JD012735.

37. Cziczo DJ, Froyd KD, Hoose C, Jensen EJ, Diao M, Zondlo MA, et al. Clarifying the dominant sources and mechanisms of cirrus cloud formation. Science. 2013;340:1320-4. doi:10.1126/science. 1234145 .

38. Haag W, Kärcher B, Ström J, Minikin A, Lohmann U, Ovarlez J, et al. Freezing thresholds and cirrus cloud formation mechanisms 
inferred from in situ measurements of relative humidity. Atmos Chem Phys. 2003;3:1791-806.

39. Kärcher B, Lohmann U. A parameterization of cirrus cloud formation: heterogeneous freezing. J Geophys Res. 2003;108(D14): 4402. doi:10.1029/2002JD003220.

40. Rosenfeld D, Woodley WL. Deep convective clouds with sustained supercooled liquid water down to $-37.5^{\circ} \mathrm{C}$. Nature. 2000;405:440-42.

41. Kärcher B, Seifert A. On homogeneous ice formation in liquid clouds. Q J R Meteorol Soc. 2016;142:1320-34. doi:10.1002/qj. 2735.

42. Stith JL, Avallone LM, Bansemer A, Basarab B, Dorsi SW, Fuchs $\mathrm{B}$, et al. Ice particles in the upper anvil regions of midlatitude continental thunderstorms: the case for frozen-drop aggregates. Atmos Chem Phys. 2014;14:1973-85. doi:10.5194/acp-141973-2014.

43. Bony S, Stevens B, Coppin D, Becker T, Reed KA, Voigt A, et al. Thermodynamic control of anvil cloud amount. Proc Natl Acad Sci U S A. 2016;113:8927-32. doi:10.1073/pnas.1601472113.

44. Kärcher B, Lohmann U. A parameterization of cirrus cloud formation: homogeneous freezing of supercooled aerosols. J Geophys Res. 2002;107:D2. doi:10.1002/2001JD000470.

45. Zhou C, Penner JE. Aircraft soot indirect effect on large-scale cirrus clouds: is the indirect forcing by aircraft soot positive or negative? J Geophys Res. 2014;119:11303-20. doi:10.1002/ 2014JD021914.

46. Penner JE, Chen Y, Wang M, Liu X. Possible influence of anthropogenic aerosols on cirrus clouds and anthropogenic forcing. Atmos Chem Phys. 2009;9:879-96.

47. Gettelman A, Liu X, Barahona D, Lohmann U, Chen C. Climate impacts of ice nucleation. J Geophys Res. 2012;117:D20201. doi: 10.1029/2012JD017950.

48. Kärcher B, Möhler O, DeMott PJ, Pechtl S, Yu F. Insights into the role of soot aerosols in cirrus cloud formation. Atmos Chem Phys. 2007;7:4203-27.

49. Zhou C, Penner JE, Lin G, Liu X, Wang M. What controls the low ice number concentration in the upper troposphere? Atmos Chem Phys. 2016;16:12411-24. doi:10.5194/acp-16-12411-2016.

50. Hendricks J, Kärcher B, Lohmann U. Effects of ice nuclei on cirrus clouds in a global climate model. J Geophys Res. 2011;116:D18206. doi:10.1029/2010JD015302.

51. Kärcher B, Hendricks J, Lohmann U. Physically based parameterization of cirrus cloud formation for use in global atmospheric models. J Geophys Res. 2006;111:D01205. doi:10.1029/ 2005JD006219.

52. Barahona D, Rodriguez J, Nenes A. Sensitivity of the global distribution of cirrus ice crystal concentration to heterogeneous freezing. J Geophys Res. 2010;115:D23213. doi:10.1029/ 2010JD014273.

53. Kuebbeler M, Lohmann U, Hendricks J, Kärcher B. Dust ice nuclei effects on cirrus clouds. Atmos Chem Phys. 2014;14: 3027-46.

54. Cziczo DJ, Froyd KD, Gallavardin SJ, Möhler O, Benz S, Saathoff H, et al. Deactivation of ice nuclei due to atmospherically relevant surface coatings. Environ Res Lett. 2009;4:044013. doi: 10.1088/1748-9326/4/4/044013

55. Abbatt JPD, Benz S, Cziczo DJ, Kanji Z, Lohmann U, Möhler O. Solid ammonium sulfate aerosols as ice nuclei: a pathway for cirrus cloud formation. Science. 2006;313:1770-3.

56. Colberg CA, Luo BP, Wernli H, Koop T, Peter T. A novel model to predict the physical state of atmospheric $\mathrm{H}_{2} \mathrm{SO}_{4} / \mathrm{NH}_{3} / \mathrm{H}_{2} \mathrm{O}$ aerosol particles. Atmos Chem Phys. 2003;3:909-24.

57. Liu X, Penner JE, Wang M. Influence of anthropogenic sulfate and black carbon on upper tropospheric clouds in the NCAR CAM3 model coupled to the IMPACT global aerosol model. J Geophys Res. 2009;114:D03204. doi:10.1029/2008JD010492.
58. Burkhardt U, Kärcher B. Global radiative forcing from contrail cirrus. Nat Clim Chang. 2011;1:54-8. doi:10.1038/nclimate1068.

59. Kärcher B. The importance of contrail ice formation for mitigating the climate impact of aviation. J Geophys Res. 2016;121:3497505. doi:10.1002/2015JD024696.

60. Boucher O, Forster PM, Gruber N, Minh H-D, Lawrence MG, Lenton TM, et al. Rethinking climate engineering categorization in the context of climate change mitigation and adaptation. Wiley Interdiscip Rev Clim Chang. 2014;5:23-35. doi:10.1002/wcc. 261.

61. National Research Council of the National Academies. Climate intervention - reflecting sunlight to cool earth. Washington DC: The National Academies Press; 2015. p. 244.

62. Mitchell DL, Finnegan W. Modification of cirrus clouds to reduce global warming. Environ Res Lett. 2009;4:045102. doi:10.1088/ 1748-9326/4/4/045102.

63. Storelvmo T, Kristjánsson JE, Muri H, Pfeffer MA, Barahona D, Nenes A. Cirrus cloud seeding has potential to cool climate. Geophys Res Lett. 2013;40:178-82. doi:10.1002/grl.50122.

64. Storelvmo T, Herger N. Cirrus cloud susceptibility to the injection of ice nuclei in the upper troposphere. J Geophys Res. 2014;119: 2375-89. doi:10.1002/2013JD020816.

65. Muri H, Kristjánsson JE, Storelvmo T, Pfeffer MA. The climatic effects of modifying cirrus clouds in a climate engineering framework. J Geophys Res. 2014;119:4174-91. doi:10.1002/ 2013JD021063.

66. Jackson LS, Crook JA, Forster PM. An intensified hydrological cycle in the simulation of geoengineering by cirrus cloud thinning using ice crystal fall speed changes. J Geophys Res. 2016;121: 6822-40. doi:10.1002/2015JD024304.

67. Storelvmo T, Boos WR, Herger N. Cirrus cloud seeding: a climate engineering mechanism with reduced side effects? Phil Trans R Soc A. 2014;372:20140116. doi:10.1098/rsta.2014.0116.

68. Kristjánsson JE, Muri $\mathrm{H}$, Schmidt $\mathrm{H}$. The hydrological cycle response to cirrus cloud thinning. Geophys Res Lett. 2015;42: 10807-15. doi:10.1002/2015GL066795.

69. Penner JE, Zhou C, Liu X. Can cirrus cloud seeding be used for geoengineering? Geophys Res Lett. 2015;42:8775-82. doi:10. 1002/2015GL065992.

70. Gasparini B, Lohmann U. Why cirrus cloud seeding cannot substantially cool the planet. J Geophys Res. 2016;121:4877-93. doi: 10.1002/2015JD024666.

71. Cirisan A, Spichtinger P, Luo BP, Weisenstein DK, Wernli H, Lohmann U, et al. Microphysical and radiative changes in cirrus clouds by geoengineering the stratosphere. J Geophys Res. 2013;118:4533-48. doi:10.1002/jgrd.50388.

72. Forbes R. Microphysics: from intricacy to simplicity. 2008; 129 48, ECMWF Seminar on Parametrization of Subgrid Physical Processes. European Centre for Medium-Range Weather Forecasts, Reading, UK.

73. DeMott PJ. Laboratory studies of cirrus cloud processes. In: Lynch DK, editor. Cirrus. 5th ed. New York: Oxford University Press; 2002. p. 102-35.

74. Mitchell DL, Rasch P, Ivanova D, McFarquhar G, Nousiainen T. Impact of small ice crystal assumptions on ice sedimentation rates in cirrus clouds and GCM simulations. Geophys Res Lett. 2008:35:L09806. doi:10.1029/2008GL033552.

75. Barahona D, Nenes A. Parameterization of cirrus formation in large scale models: homogeneous nucleation. J Geophys Res. 2008;113:D11211. doi:10.1029/2007JD009355.

76. Morrison H, Gettelman A. A new two-moment bulk stratiform cloud microphysics scheme in the Community Atmosphere Model, Version 3 (CAM3). Part I: description and numerical tests. J Clim. 2008;21:3642-59.

77. Barahona D. A. Molod J, Bacmeister A, Nenes A, Gettelman A, Morrison H, Phillips V, Eichmann A. Development of two- 
moment cloud microphysics for liquid and ice within the NASA Goddard Earth Observing System Model (GEOS-5). Geosci Model Dev. 2014;7:1733-66. doi:10.5194/gmd-7-1733-2014.

78. Köhler CG, Seifert A. Identifying sensitivities for cirrus modelling using a two-moment two-mode bulk microphysics scheme. Tellus Ser B Chem Phys Meteorol. 2015;64:24494. doi:10.3402/tellusb. v67.24494.

79. Bardeen CG, Gettelman A, Jensen EJ, Heymsfield A, Conley AJ, Delanoë J, et al. Improved cirrus simulations in a general circulation model using CARMA sectional microphysics. J Geophys Res. 2013;118:11,679-97. doi:10.1002/2013JD020193.

80. Dean SM, Flowerdew J, Lawrence BN, Eckermann SD. Parameterisation of orographic cloud dynamics in a GCM. Clim Dyn. 2007;28:581-97. doi:10.1007/s00382-006-0202-0.

81. Joos H, Spichtinger P, Lohmann U, Gayet J-F, Minikin A. Orographic cirrus in the global climate model ECHAM5. J Geophys Res. 2008;113:D18205. doi:10.1029/2007JD009605.

82. DeMott PJ, Cziczo DJ, Prenni AJ, Murphy DM, Kreidenweis SM, Thomson DS, et al. Measurements of the concentration and composition of nuclei for cirrus formation. Proc Natl Acad Sci U S A. 2003;100:14655-60. doi:10.1073/pnas.2532677100.

83. Kärcher B, Dörnbrack A, Sölch I. Supersaturation variability and cirrus ice crystal size distributions. J Atmos Sci. 2014;71:290526. doi:10.1175/JAS-D-13-0404.1.

84. Jensen EJ, Ueyama R, Pfister L, Bui TV, Alexander MJ, Podglajen A, et al. High-frequency gravity waves and homogeneous ice nucleation in tropical tropopause layer cirrus. Geophys Res Lett. 2016;43:6629-35. doi:10.1002/2016GL069426.

85. Kärcher B, Burkhardt U. A cirrus cloud scheme for general circulation models. Q J R Meteorol Soc. 2008;134:1439-61. doi:10. 1002/qj.301.

86. Burkhardt U. Extending a PDF cloud scheme in order to accommodate cirrus physics. 2012; 99-107, ECMWF Workshop on Parametrization of Clouds and Precipitation. European Centre for Medium-Range Weather Forecasts, Reading, UK.

87. Lohmann U. Representing cloud-aerosol interactions in GCMs. 2012; 71-7, ECMWF Workshop on Parametrization of Clouds and Precipitation. European Centre for Medium-Range Weather Forecasts, Reading, UK.

88. Spichtinger P, Gierens KM. Modelling of cirrus clouds-Part 1b: structuring cirrus clouds by dynamics. Atmos Chem Phys. 2009;9: 707-19.

89. Jensen EJ, Pfister L, Toon OB. Impact of radiative heating, wind shear, temperature variability, and microphysical processes on the structure and evolution of thin cirrus in the tropical tropopause layer. J Geophys Res. 2011;116:D12209. doi:10.1029/ 2010JD015417.

90. Murphy DM. Rare temperature histories and cirrus ice number density in a parcel and a one-dimensional model. Atmos Chem Phys. 2014;14:13013-22.

91. Dinh T, Podglajen A, Hertzog A, Legras B, Plougonven R. Effect of gravity wave temperature fluctuations on homogeneous ice nucleation in the tropical tropopause layer. Atmos Chem Phys. 2016;16:35-46.

92. Zhang C, Harrington JY. The effects of surface kinetics on crystal growth and homogeneous freezing in parcel simulations of cirrus. J Atmos Sci. 2015;72:2929-46.

93. Baran AJ. From the single-scattering properties of ice crystals to climate prediction: a way forward. Atmos Res. 2012;112:45-69. doi:10.1016/j.atmosres.2012.04.010.
94. Yang P, Liou K-N, Bi L, Liu C, Yi B, Baum BA. On the radiative properties of ice clouds: light scattering, remote sensing, and radiation parameterization. Adv Atmos Sci. 2015;32:32-63.

95. Dickson NC, Gierens KM, Rogers HL, Jones RL. Probabilistic description of ice-supersaturated layers in low resolution profiles of relative humidity. Atmos Chem Phys. 2010;10:6749-63.

96. Bony S, Stevens B, Frierson DMW, Jakob C, Kageyama M, Pincus R, et al. Clouds, circulation and climate sensitivity. Nat Geosci. 2015;8:261-8. doi:10.1038/ngeo2398.

97. Norris JR, Allen RJ, Evan AT, Zelinka MD, O’Dell CW, Klein SA. Evidence for climate change in the satellite cloud record. Nature. 2016;536:72-5. doi:10.1038/nature18273.

98. Li Y, Thompson DWJ. The signature of the stratospheric BrewerDobson circulation in tropospheric clouds. J Geophys Res Atmos. 2013;118:3486-94. doi:10.1002/jgrd.50339.

99. Davis SM, Liang CK, Rosenlof KH. Interannual variability of tropical tropopause layer clouds. Geophys Res Lett. 2013;40: 2862-6. doi:10.1002/grl.50512.

100. Moseley C, Hohenegger C, Berg P, Haerter JO. Intensification of convective extremes driven by cloud-cloud interaction. Nat Geosci. 2016;9:748-52. doi:10.1038/ngeo2789.

101. Haladay T, Stephens G. Characteristics of tropical thin cirrus clouds deduced from joint CloudSat and CALIPSO observations. J Geophys Res. 2009;114:D00A25. doi:10.1029/2008JD010675.

102. Delanoë J, Hogan RJ. Combined CloudSat-CALIPSO-MODIS retrievals of the properties of ice clouds. J Geophys Res. 2010;115:D00H29. doi:10.1029/2009JD012346.

103. Berry E, Mace GG. Cirrus cloud properties and the large-scale meteorological environment: relationships derived from A-Train and NCEP-NCAR reanalysis data. J Appl Meteorol Climatol. 2013;52:1253-76. doi:10.1175/JAMC-D-12-0102.1.

104. Plant RS, Craig GC. A stochastic parameterization for deep convection based on equilibrium statistics. J Atmos Sci. 2008;65:87105.

105. Randall D, Khairoutdinov M, Arakawa A, Grabowski W. Breaking the cloud parametrization deadlock. Bull Am Meteorol Soc. 2003;84:1547-64.

106. Vernier J-P, Fairlie TD, Natarajan M, Wienhold FG, Bian J, Martinsson BG, et al. Increase in upper tropospheric and lower stratospheric aerosol levels and its potential connection with Asian pollution. J Geophys Res. 2015;120:1608-19. doi:10.1002/ 2014JD022372.

107. Yu P, Toon OB, Neely RR, Martinsson BG, Brenninkmeijer CAM. Composition and physical properties of the Asian Tropopause Aerosol Layer and the North American Tropospheric Aerosol Layer. Geophys Res Lett. 2015;42:2540 6. doi:10.1002/2015GL063181.

108. Bond TC et al. Bounding the role of black carbon in the climate system: a scientific assessment. J Geophys Res. 2013;118:5380 552. doi:10.1002/jgrd.50171.

109. DeMott P, Möhler O, Stetzer O, Vali G, Levin Z, Petters MD, et al. Resurgence in ice nuclei measurement research. Bull Am Meteorol Soc. 2011;92:1623-35. doi:10.1175/2011BAMS3119.1.

110. Feingold G, McComiskey A, Yamaguchi T, Johnson JS, Carslaw KS, Schmidt KS. New approaches to quantifying aerosol influence on the cloud radiative effect. Proc Natl Acad Sci U S A. 2016;113:5812-9. doi:10.1073/pnas.1514035112. 